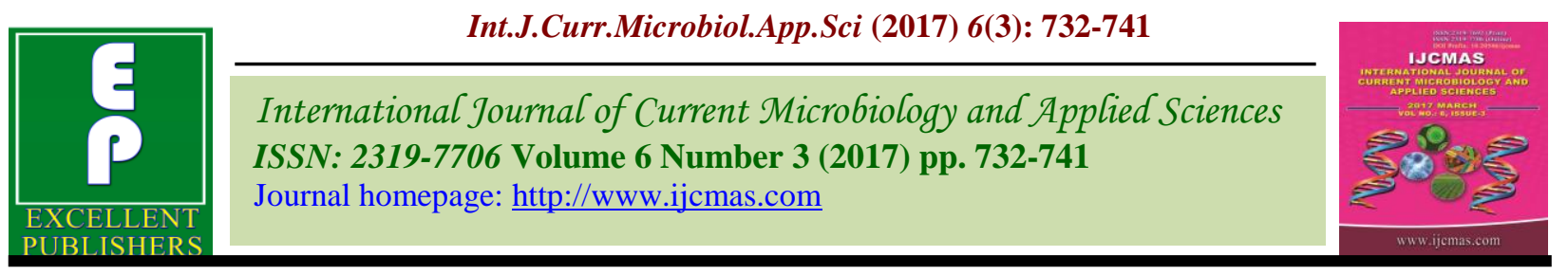

Original Research Article https://doi.org/10.20546/ijcmas.2017.603.085

\title{
Seroprevalence of Toxoplasmosis in Antenatal Women with Bad Obstetric History
}

\author{
N. Sridevi*, B. Nirmala Grace, B. Venkat Rao and P. Kamala \\ Department of Microbiology, Osmania Medical College, Koti, Hyderabad, Telangana, India \\ *Corresponding author:
}

\begin{abstract}
A B S T R A C T
Keywords

Toxoplasma gondii, Bad obstetric history, ELISA, Seroprevalence.

Article Info

Accepted:

15 February 2017

Available Online:

10 March 2017

Toxoplasmosis is a zoonosis caused by Toxoplasma gondii, an obligate intracellular parasite. It can cause significant morbidity and mortality in the developing fetus if the pregnant women get acute infection during pregnancy. The aim of the study was to assess the seroprevalence of Toxoplasmosis in antenatal women with bad obstetric history. The seropositivity was analysed according to age, bad obstetric history, socioeconomic and literacy status. A total of 160 antenatal women with $\mathrm{BOH}$ and 24 antenatal women with previous normal delivery as control group attending to Govt. General Hospital, Guntur. The serum samples were collected and tested for presence of specific IgM antibodies using a commercial ELISA kit. The seroprevalence of IgM antibodies was $26(16.25 \%)$ in antenatal women with $\mathrm{BOH}$ and 0 among the control group. Abortion (53.85\%) was the commonest form of BOH followed by still births (19.23\%).Various risk factors such as people living in rural areas, low socioeconomic status \& illiteracy had greater association of risk of toxoplasmosis than urban population, high socioeconomic status and literacy. This study concluded that there is correlation between toxoplasma infection and Bad obstetric history and abortion is the major cause of fetal loss in pregnant women with bad obstetric history. A previous history of pregnancy wastage $\&$ the serological reaction for toxoplasmosis during current pregnancy must be considered while managing $\mathrm{BOH}$ cases so as to reduce the adverse outcome.
\end{abstract}

\section{Introduction}

Bad Obstetric History (BOH) implies previous unfavourable fetal outcome in terms of two or more consecutive spontaneous abortions, history of intra uterine fetal death, intra uterine growth retardation, still birth, early neonatal death or congenital anomalies (Kumari et al., 2011).

The Causes of bad obstetric history $(\mathrm{BOH})$ may be genetic, hormonal, abnormal maternal immune response and maternal infections (Turbadkar et al., 2003). Infection caused by
TORCH (Toxoplasma gondii, Rubella virus, Cytomegalovirus and Herpes SimplexVirus) are one of the major causes for bad obstetrichistory (BOH) (Mc cabe, 1988). These are a group of viral, bacterial and protozoan infections that gain access to the fetal blood stream transplacentally via the chorionic villi. The pathogens usually cause only asymptomatic or mild infections in mother, but can cause much more serious consequences in fetus (Kaur et al., 1999). Toxoplasmosis is caused by an obligate 
intracellular protozoan parasite Toxoplasma gondii (Parija, 2008). It is one of the most common parasitic infections of humans and other warm- blooded animals. Approximately one- third of the population is exposed to this parasite. Infection in an immunocompetent adult human is usually asymptomatic. Toxoplasma is most dangerous for immunocompromised patients and the fetus whose mother is infected during pregnancy (Pinard et al., 2003).

Transmission of the infection to the fetus usually occurs when primary infection is acquired by an immunologically normal mother during gestation. Infected pregnant are often asymptomatic or many have only mild symptoms, making the diagnosis difficult. Infection may be transmitted to the fetus transplacentally (McLeod et al., 2000). The risk of congenital toxoplasmosis depends on the timing of the mother's acute infection. The disease usually severe when acquired in the first trimester, and the severity decreases as the gestational age advances, leading to a mild or an in apparent disease at birth. The different rates of transmission and outcomes are most likely related to placental blood flow, the virulence and amount of $T$. gondii acquired, and the immunologic ability of the mother to restrict parasitaemia.

The overall rate of transmission of maternal infection to the fetus is about $45 \%$, of these $60 \%$ are subclinical infections, $9 \%$ resulting in deaths of the fetus, and $30 \%$ have severe damage (Singh, 2003).

The clinical implications of infections due to Toxoplasma in pregnant patients are manifold. Such patients may have spontaneous abortions, still births, intra uterine growth retardation, preterm deliveries or foetal anomalies (Zargar et al., 1998). Various manifestations of congenital infections may occur in the perinatal period.
These range from relatively mild signs, such as prematurity, peripheral retinal scars, sensory deficits, developmental delay, impaired psychomotor performance, and maternal retardation to the classic triad of signs consisting of hydrocephalus, intracerebral calcification and choriretinits.

Toxoplasmosis is usually by serological tests Toxoplasma-specific IgM and $\mathrm{IgG}$ antibodies. A positive IgG titre is sufficient to establish that a patient has been infected with $T$. gondii but a negative IgM result virtually ruleout a recently acquired infection, unless sera tested so early when an antibody response has not yet developed or is undectable.

The present study was conducted to determine the seropositivity of toxoplasmosis is antenatal women with bad obstetric history $(\mathrm{BOH})$ and to compare it with that in antenatal women having previous normal obstetric history attending the antenatal OPD of tertiary care hospital in Guntur, Guntur medical college.

\section{Materials and Methods}

A total number of 184 blood samples were collected from antenatal women who attended Govt. General Hospital, Guntur during the period April2013 - April 2014.out of the 184 samples, 160 samples were included in the study group from patients with previous $\mathrm{BOH}$, and 24 were included in the control group from antenatal women with previous normal delivery.

Pregnant women without bad obstetric history were excluded. All the samples were analysed for anti Toxoplasma specific IgM antibodies by using RD- Ratio Diagnostics, kits (manufactured by Germany) following instruction details as per kit insert in the Department of Microbiology, Guntur Medical College, Guntur. 
Reagents of Toxoplasma IgM ELISA Kit
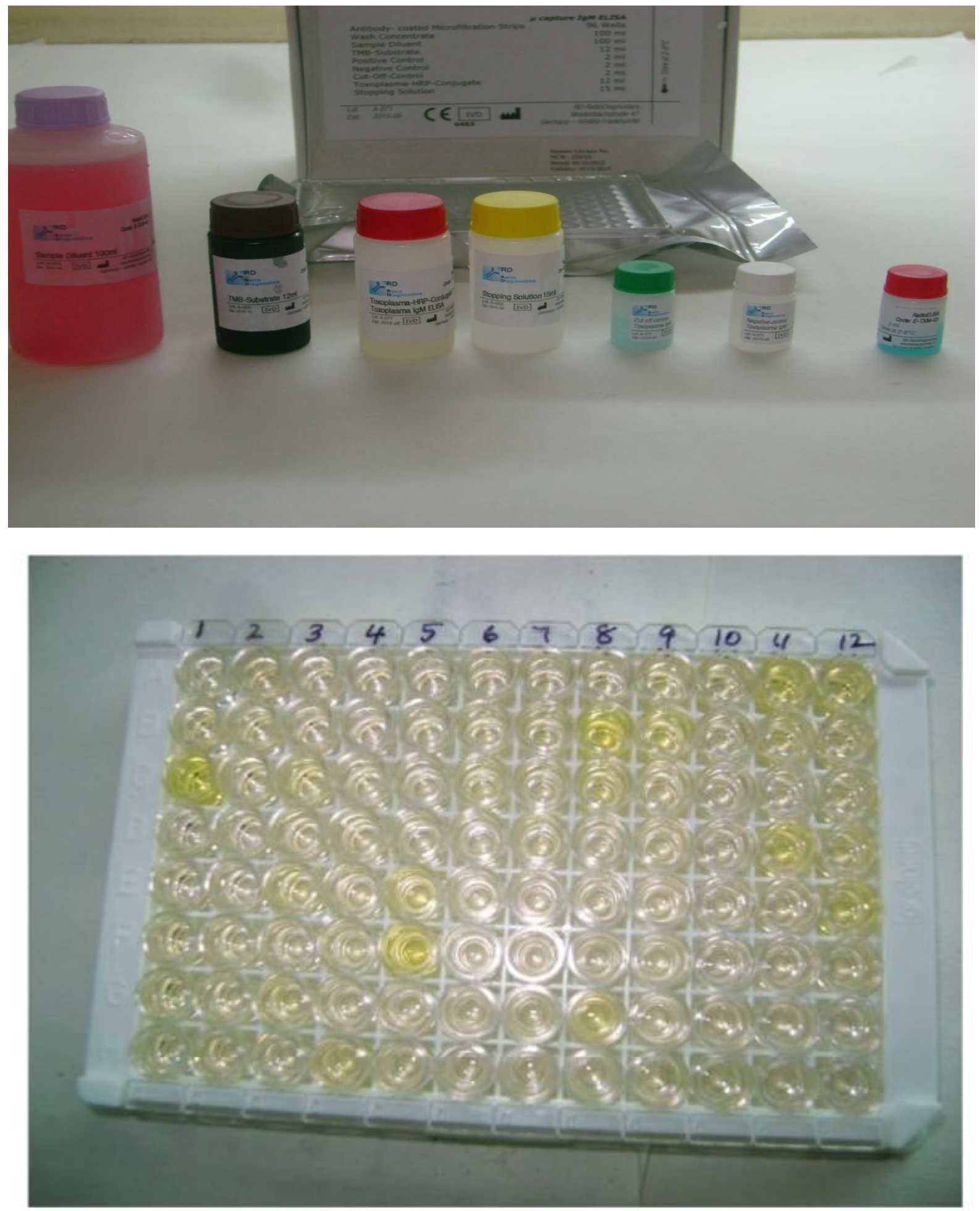

Result after adding stop solution 


\section{Results and Discussion}

Among 160 B.O.H cases, 26 (16.25\%) were seropositive for Toxoplasma specific IgM antibodies and $134 \quad(83.75 \%)$ were seronegative for IgM antibodies. In the control group, none of the samples were positive for IgM antibodies to $T$. gondii (Table 1).

Among total 26 seropositive cases abortions had the maximum incidence with 14 (53.84\%) cases. The next major incidence was observed in cases with still births i.e. $5(19.23 \%)$ cases. Intra-uterine deaths have the incidence of 4 $(15.38 \%)$ cases followed by preterm deliveries with 2 (7.69\%) cases and congenital anomalies with 1 (3.84\%) case (Table 2).

Out of 26 seropositive cases, 15 cases are observed in 20-24 years age group which is high incidence. Also, 7 cases are observed in 25-29 years of age group. 1 case is observed in 15-19 years of age group and 3 cases are observed in 30-34 years of age group. Among total 26 seropositive cases, 14 cases were observed in first trimester, 10 cases in second
Trimester and 2 cases are in third Trimester (Table 3). Majority of cases are observed in low-socio economic status i.e. 22 (84.62\%) cases out of total 26 seropositive cases. And only $4(15.38 \%)$ cases were observed in middle-socio economic status.

The observation on distribution of seropositivity according to their residential area status, out of 26 cases, 18 (69.23\%) cases are observed in rural areas and $8(30.77 \%)$ cases in urban area. Out of 26 positive cases, $14(53.84 \%)$ antenatal women are illiterates, $10(38.46 \%)$ cases belong to 5 th to graduation and 2 cases are up to $5^{\text {th }}$ standard.

Maternal infection play a critical role in pregnancy wastage and its prevalence in patients with $\mathrm{BOH}$ or complicated pregnancy is a significant risk factor.

Toxoplasmosis is a zoonotic disease with worldwide distribution. Most Toxoplasma associated infections among people occur by ingesting tissue cysts from infected meat or oocysts from soil or by congenital transmission through the placenta.

Table.1

\section{Seroprevalence of Toxoplasmosis in study \& control group}

\begin{tabular}{|c|c|c|c|}
\hline Group & $\begin{array}{c}\text { No. of Samples } \\
\text { Tested }\end{array}$ & No. of Positives & Percentage \\
\hline $\mathrm{BOH}$ & 160 & 26 & 16.25 \\
\hline Control & 24 & Nil & Nil \\
\hline
\end{tabular}


Table. 2

The seropositivity of Toxoplasmosis among various groups of bad obstetric History.

\begin{tabular}{|l|c|c|c|}
\hline \multicolumn{1}{|c|}{$\begin{array}{c}\text { Bad Obstetric } \\
\text { History }\end{array}$} & $\begin{array}{c}\text { No. of Samples } \\
\text { Tested }\end{array}$ & No. of Positives & Percentage \\
\hline Abortions & 88 & 14 & $53.85 \%$ \\
\hline IUD & 27 & 4 & $15.38 \%$ \\
\hline Still Births & 23 & 5 & $19.23 \%$ \\
\hline Pre-term & 14 & 2 & $7.69 \%$ \\
deliveries & 8 & 1 & $3.85 \%$ \\
\hline Congenital & & & \\
\hline Tonomalies & 160 & 26 & $16.25 \%$ \\
\hline
\end{tabular}

Table.3

Seropositivity of Toxoplasmosis among B.O.H cases according to gestational age

\begin{tabular}{|l|c|c|c|}
\hline Gestational Age & $\begin{array}{c}\text { Total No. of } \\
\text { cases }\end{array}$ & $\begin{array}{c}\text { No. of Positive } \\
\text { cases }\end{array}$ & Percentage \\
\hline I Trimester & 57 & 14 & $53.85 \%$ \\
\hline II Trimester & 74 & 10 & $38.46 \%$ \\
\hline III Trimester & 29 & 2 & $7.69 \%$ \\
\hline Total & $\mathbf{1 6 0}$ & $\mathbf{2 6}$ & $\mathbf{1 6 . 2 5 \%}$ \\
\hline
\end{tabular}


Table.4

Seropositivity of Toxoplasmosis in various studies

\begin{tabular}{|c|c|c|c|c|c|}
\hline Year & Study & Region & No. of Samples Tested & No. of Positive Samples & Percentage \\
\hline 2001 & P. Yashodhara et al & Hyderabad & 175 & 23 & $13.1 \%$ \\
\hline 2003 & D. Turbadkar et al & Mumbai & 380 & 40 & $10.52 \%$ \\
\hline 2004 & Shashichopra et al & Amritsar & 200 & 85 & $42.5 \%$ \\
\hline 2006 & Rajendra B. Surapam & Nagpur & 150 & 22 & $14.66 \%$ \\
\hline 2009 & N. Sood et al & Ahmedabad & 349 & 144 & $41.3 \%$ \\
\hline 2006 & S. Khurana et al & Chandigarh & 300 & 9 & $3 \%$ \\
\hline 2007 & D.A. Mousa et al & Libya & 143 & 12 & $8.4 \%$ \\
\hline 2007 & Srirupa et al & Kolkata & 50 & 09 & $18 \%$ \\
\hline 2010 & Malarvizhi et al & \begin{tabular}{|l|} 
Salem \\
Tamil Nadu \\
\end{tabular} & 232 & 9 & $3.9 \%$ \\
\hline 2014 & Present Study & Guntur & 160 & 13 & $16.25 \%$ \\
\hline
\end{tabular}

Table.5

Comparison of Seropositivity of Toxoplasmosis according to B.O.H in various studies

\begin{tabular}{|c|c|c|}
\hline Study & High Prevalence & $\begin{array}{c}\% \text { of Positive } \\
\text { cases }\end{array}$ \\
\hline \multirow{4}{*}{$\begin{array}{l}\text { Rajendra B Sarpam et } \\
\text { al (2006) }\end{array}$} & Abortions (12/22) & $54.5 \%$ \\
\hline & Still births $(3 / 22)$ & $13.63 \%$ \\
\hline & Congenital anomalies (1/22) & $4.55 \%$ \\
\hline & Preterm deliveries (2/22) & $9.09 \%$ \\
\hline \multirow{4}{*}{$\begin{array}{l}\text { Shashi Chopra et al } \\
(2009)\end{array}$} & Abortions (61/85) & $71.8 \%$ \\
\hline & Still births (11/85) & $12.94 \%$ \\
\hline & Congenital anomalies (4/85) & $4.71 \%$ \\
\hline & Preterm deliveries $(8 / 85)$ & $9.41 \%$ \\
\hline \multirow[t]{4}{*}{ Present Study } & Abortions (14/26) & $53.85 \%$ \\
\hline & Still births (5/26) & $19.23 \%$ \\
\hline & Congenital anomalies (1/26) & $3.85 \%$ \\
\hline & Preterm deliveries (2/26) & $7.69 \%$ \\
\hline
\end{tabular}


Table.6

Seropositivity of Toxoplasmosis according to Age in Comparison with

Other studies

\begin{tabular}{|l|l|l|}
\hline Study & High Prevalence & $\begin{array}{l}\% \text { of Positive } \\
\text { cases }\end{array}$ \\
\hline S.Khurana et al (2010) & $15-19$ years & $44.4 \%$ \\
\hline N. Sood et al (2009) & $20-24$ years & $38.19 \%$ \\
\hline D.A. Mousa et al (2011) & $35-40$ years & $50 \%$ \\
\hline Malarvizhi A et al (2012) & $30-34$ years & $55.5 \%$ \\
\hline M.Fallah et al (2008) & $20-24$ years & $38.7 \%$ \\
\hline Present Study & $20-24$ years & $53.84 \%$ \\
\hline
\end{tabular}

Table.7

Seropositivity of Toxoplasmosis according to Gestational Period in comparison with other studies

\begin{tabular}{|c|c|c|}
\hline Study & Prevalence & $\begin{array}{c}\% \text { of Positive } \\
\text { cases }\end{array}$ \\
\hline \multirow{3}{*}{ Sri Rupa et al (2011) } & I Trimester (6/9) & $66.7 \%$ \\
\hline & II Trimester (3/9) & $33.3 \%$ \\
\hline & III Trimester $(0 / 9)$ & $0.00 \%$ \\
\hline \multirow{3}{*}{ Malarvizhi et al (2012) } & I Trimester (4/9) & $44.4 \%$ \\
\hline & II Trimester (5/9) & $55.6 \%$ \\
\hline & III Trimester $(0 / 9)$ & $0.00 \%$ \\
\hline \multirow{3}{*}{ BasimMosaHussan et al (2013) } & I Trimester (23/32) & $71.88 \%$ \\
\hline & II Trimester (9/32) & $28.12 \%$ \\
\hline & III Trimester $(0 / 32)$ & $0.00 \%$ \\
\hline \multirow{3}{*}{ Present Study } & I Trimester (14/26) & $53.85 \%$ \\
\hline & II Trimester $(10 / 26)$ & $38.46 \%$ \\
\hline & III Trimester (2/9) & $7.69 \%$ \\
\hline
\end{tabular}


Table.8

Comparison of Seropositivity of Toxoplasmosis according to Socio-

Economic Status

\begin{tabular}{|l|l|l|}
\hline \multicolumn{1}{|c|}{ Study } & \multicolumn{1}{|c|}{ Prevalence } & $\%$ of Positive cases \\
\hline \multirow{3}{*}{$\begin{array}{l}\text { SuryamaniChintapalli et al } \\
(2013)\end{array}$} & Lower (26/31) & $83.8 \%$ \\
\cline { 2 - 3 } & Middle (9/16) & $56.2 \%$ \\
\cline { 2 - 3 } & Higher (1/5) & $29.0 \%$ \\
\hline \multirow{3}{*}{ Present Study } & Lower(22/26) & $84.61 \%$ \\
\cline { 2 - 3 } & Middle(4/26) & $15.38 \%$ \\
\cline { 2 - 3 } & Higher (0) & 0 \\
\hline
\end{tabular}

Table.9

Seropositivity of Toxoplasmosis according to Residential status in comparison with other studies

\begin{tabular}{|l|l|l|}
\hline \multicolumn{1}{|c|}{ Study } & \multicolumn{1}{c|}{ Prevalence } & \multicolumn{1}{c|}{$\begin{array}{c}\text { cos Positive } \\
\text { cases }\end{array}$} \\
\hline \multirow{2}{*}{ Ali H.M.Al-Marzoqi et al (2009) } & Urban (27/100) & $27.0 \%$ \\
\cline { 2 - 3 } & Rural $(73 / 100)$ & $73.0 \%$ \\
\hline \multirow{2}{*}{ Malarvizhi et al (2012) } & Urban (2/9) & $22.3 \%$ \\
\cline { 2 - 3 } & Rural $(7 / 9)$ & $77.7 \%$ \\
\hline \multirow{2}{*}{ Present Study } & Urban (8/26) & $30.76 \%$ \\
\cline { 2 - 3 } & Rural (18/26) & $69.24 \%$ \\
\hline
\end{tabular}


The seropositivity levels vary widely in different regions of the globe. The rates of prevalence change according to the nutritional factors, sociocultural habits, geographical factors, climate, transmission route and typically rise with age (Coelho et al., 2003).

In the present study, among 160 test samples $16.25 \%$ were IgM antibodies to $T$. gondii which correlates with the Sri Rupa et al., (2011)18\%, Rajendra surupam et al., (2006) $14.66 \%$, Yasadhara et al., 13.1\%, Turbhadhkar et al., (2003) $10.52 \%$ whereas Mousa et al. (2011), Malarvizhi et al., (2012) reported very low levels of $8.4 \%$ \& $3.9 \%$. Very high levels of seropositivity were reported by Shashi Chopra et al., (2009) and Sood et al., (2004) reported $42.5 \%$ \& $41.3 \%$ respectively (Table 4).

In the present study seropositivity was observed in lower socioeconomic status $84.6 \%$ which correlates with Suryamani et al., (2013) 83.8\% (Table 5, 6, 7, 8, 9). in the present study seropositivty was observed more in rural areas $69.24 \%$ which correlates with Ali Marzoqui et al., (2012) $73 \%$ and Malar vizhi et al., (2012) 77.7\%.

In conclusion,

1. Based on this study, the information obtained about the prevalence of Toxoplasmosis in this area $(16.25 \%)$, could help to estimate the real magnitude of the problem and investigative measures should be taken to undertake a multi-centric study as well as compulsory screening for antenatal check-up.

2. A previous history of pregnancy wastage and the seropositivity of Toxoplasmosis during the current pregnancy must be considered while managing $\mathrm{BOH}$ cases so as to reduce the adverse fetal outcome.

3. All pregnant women should be screened for Toxoplasmosis and educated on predisposing risk factors during their antenatal visits.

4. The education of pregnant women about transmission route and measures seems to be the only effective way to protect seronegative women from Toxoplasmosis.

\section{References}

Ali, H., M. Marzoqi, Raad, A. Kadhim, Diyar, K. F.A.I. Janabi Hussein, J. Hussein, Zahraa M. 2012. Seroprevalence study of IgG \& IgM antibodies to TORCH in pregnancy women in Babylon province, J. Biol. Agri. Health Care, Vol 2, No.10.

Coelho, R.A., Kobayashi, M., Carvalho, L.B., Jr. 2003. Prevalence of IgG antibodies specific to Toxoplasma gondii among blood donors in Recife, northeast Brazil. Rev. Inst. Med. Trop. Sao Paulo, 45: 229-31.

Flegr, J., Preiss, M., Klose, J., Havlicek, J., Vitakova, M., Kodym, P. 2003. Decreased level of psychobiological factor novelty seeking and lower intelligence in men latently infected with the protozoan parasite Toxoplasma gondii Dopamine, a missing link between schizophrenia and toxoplasmosis. Biol. Psychol., 63: 253-68.

Kaur, R.N., Gupta, D., Nair, M., Kakkar, Mathur, M.D. 1999. Screening for TORCH infections in pregnant women: A report from Delhi. Southeast Asian J. Trop. Med. Public health, 30(2): 284-86.

Kumari, N., Morris, N., Dutta, R. 2011. Is screening of TORCH worthwhile in women with bad obstetric history? An observation from eastern Nepal. J. Health, Population and Nutri., 29(1): 77-80.

Malarvizhi, A., Viswanatham, T., Lavanya, V., et al. 2012. Seroprevalence of Toxoplasma gondii in Pregnant Women. J. Public Health \& Epidemiol., Vol 4(6) PP 170-177.

Mc cabe, R., Remington, J.S. 1988. Toxoplasmosis. The time has come. $N$ Engl. J. Med., 318: 313-15.

McLeod, R., Remington, J.S. 2000. Toxoplasmosis (Toxoplasmagondii). In: Behrman RE, Kliegman RM, JensonHB, editors. Nelson Textbook of pediatrics. 16th 
ed. Philadelphia, PA: WB Saunders, 105462.

Mousa, M.A. Mohammad, A.B. Toboli. 2011. Toxoplasma gondii Infection in Pregnant Women with Previous Adverse Pregnancy Outcome. Med. J. Islamic World Acad. Sci., 19-2, 95-102.

Parija, S.C. 2008. Textbook of medical parasitology. 3rd ed. Chennai: All India Publishers and Distributers, 172-81.

Pinard, J.A., Leslie, N.S., Irvine, P.J. 2003. Maternal serologic screening for toxoplasmosis. J. Midwifery Womens Health, 48: 308-16.

Rajendra, B., Surpam, Usha, P., Kamlakar, R.K. Khadse. 2006. Serological study for TORCH Infections in Women with Bad Obstetric History. J. Obstetrics \& Gynaecol. India. Vol. 56, 1:January/February 2006 Pg. $41-43$.

Razzak, A.H., Wais, S.A., Saeid, A.Y. 2005. Toxoplasmosis: the innocentsuspect of pregnancy wastage in Duhok, Iraq. East Mediterr Health J., 11: 625-32.

Shashi Chopra, Usha Arora, Aruna Agarwal. 2004. Prevalence of IgM Antibodies to Toxoplasma, Rubella and Cytomegalovirus Infections during Pregnancy. J.K. Sci., Vol.6 No.4, 190-192.

Shashi, C., Usha, A., Aruna, A. 2004. Prevalence of IgM antibodies to Toxoplasma, Rubella and Cytomegalovirus infections during pregnancy. JK. Sci., 6(4): 190-93.

Singh, S. 2003. Mother-to-child transmission and diagnosis of Toxoplasma gondii infection during pregnancy. Indian J. Med. Microbiol., 21: 69-76.

Sood, N., S. Soni, M. Vegad, P. Gupta. 2009. Seroprevalence of Toxoplasma gondii in Women with Bad Obstetric History in Ahmedabad. Gujarat Med. J., Vol.64 No.2, 35-37.

Sri Rupa Pal, Nibedita das, D. 2006. PalSeroprevalence and risk factors of Toxoplasmagondii in pregnant women in Kolkata, India - J. Recent Adv. Appl. Sci., (JRAAS), 26: 27-33.

Suryamani Chintapalli, I., Jyothi Padmaja. 2013. Seroprevalence of Toxoplasmosis in antenatal Women with bad obstetric history. Trop. Parasitol., 3(1): 62-66.

Turbadkar, D., M. Mathur, M. Rele. 2003. Seroprevalence of torch Infection in bad obstetric history. Indian J. Med. Microbiol., 21: 108-110.

Turbadkar, D., Mathur, M., Rele, M. 2003. Seroprevalence of torch infection in bad obstetric history. Indian J. Med. Microbiol., 21: 108-110.

Yashodhara, P., B.A. Ramalakshmi, A.N. Naidu, L. Raman. 2001. Prevalence of specific IgM due to Toxoplasma, Rubella, CMV and C.trachomatis Infections during Pregnancy. Indian J. Med. Microbiol., vol19 no.(2).

Zargar, A.H., Masoodi, S.R., Laway, B.A., Sofi, B.A., Wani, A.I. 1998. Seroprevalence of toxoplasmosis in women with repeated abortions in Kashmir. J. Epidemiol. Community Health, 52: 135-6.

\section{How to cite this article:}

Sridevi, N., B. Nirmala Grace, B. Venkat Rao, Kamala, P. 2017. Seroprevalence of Toxoplasmosis Inantenatal Women with Bad Obstetrichistory. Int.J.Curr.Microbiol.App.Sci. 6(3): 732-741. doi: https://doi.org/10.20546/ijcmas.2017.603.085 